described as "lymphadenosis with brown pigmentation of the skin" (characteristic of Addison's disease). On postmortem examination the suprarenal bodies were found perfectly normal, but the semilunar ganglia and solar plexus were involved in a closely aggregated mass of enlarged glands It must not be forgotten, however, that longcontinued scratching will itself lead to pigmentation, and it is a curious fact that in Sir G. E. Paget's case the patient complained much of irritation on the palms of the hands and soles of the feet, and marks of scratching were noticed on several parts of the body.

We have purposely avoided any discussion of the pruriginous or other skin affections of leukæmia as distinguished from lymphadenoma, but for the convenience of those who are interested in the subject we may refer to Nékám's publication already mentioned and to a long article on the subject, with an elaborate bibliography, by Pinkus. ${ }^{3}$

\section{CONGENITAL HEPATIC CIRRHOSIS WITH OBLITERATION OF THE BILE-DUCTS.}

By G. PARKER, M.A., M.D. Cantab., ASSISTANT PHYSICIAN TO THE GENERAL HOSPITAL, BRISTOL.

With Notes of Additional Cases BY E. L. Walker DUNBAR, M.D. ZURICH, AND THEODORE FISHER, M.D., M.R.C.P. LoND.

THE recent papers of Rolleston, Ford, and others, with the older researches of $\mathrm{J}$. Thomson, show the importance of these somewhat rare cases. It is possible that they may throw light on the problems of the production of biliary cirrhosis in the adult or explain some of the obscure forms of cirrhosed liver in older children, whether we finally regard them as due to congenital absence of the bile-ducts or to obstruction by calculi or to a poison in the foetal blood acting on the liver-cells and on the bile-ducts. The following case illustrates many of the points which have been raised by previous observers.

CASE 1.-A male infant was under my observation from Feb. 27th, 1901, till his death, at the age of six months, on April 27th. He seemed quite well and strong when born and was fed at the breast for two weeks or more. He had no jaundice and passed at first meconium and then yellow stools, but in the third week violent vomiting occurred for several days. He was in consequence weaned, but became jaundiced and the stools changed to a white hue. About Jan. 1st he had been placed under the care of Dr. E. L. Walker Dunbar for six weeks and was then admitted by her into the Women's Hospital for 14 days. Dr. Dunbar writes that at that time he took food well and passed stools quite devoid of bile, and white, except when ox-gall or calomel had been administered. In the hospital he was fed at first with milk-and-water, then with condensed milk, and finally with Nestlé's food. In the first week he gained weight. but having lost again during the second week he was sent home to be under his mother's care, and the unfavourable diagnosis was made known to her. When seen by me at the General Hospital on Feb. 27th he was well nourished but deeply jaundiced and the stools continued quite white. The abdomen was slightly distended, but nothing else abnormal could be detected. Later the jaundice became of a brownish tint, and the liver and spleen were moderately enlarged and distinctly paIpable. 'There were no symptoms of syphilis. He was treated as an outpatient for about seven weeks, receiving liquor hydrargyri, Scott's emulsion, and other preparations, and with the exception of occasional dyspeptic troubles and the slightly increasing jaundice his health remained good. On April 25th he seemed failing; slight ascites occurred, though without enlargement of the abdominal veins ; there was some irritation of the skin over the chest, otitis media was noted, and the mother reported that a little blood had been passed per rectum. He was taken into the hospital. On admission he appeared to be fairly vigorous and took his meals well, but the urine was deeply tinted and contained numerous granuiar casts. The stools became yellow again, possibly from admixture with the urine, and he died suddenly on the 27th.

As regards the family history the mother stated that she

3 Archiv für Dermatologie und Syphilis, October, 1899. had always enjoyed good health except for occasional attacks of tonsillitis. Her first pregnancy had miscarried, in the second she had twins, and in the third she had a healthy child, all of whom were still alive. During her last pregnancy she suffered much from what she took to be dyspeptic troubles and was confined to the house for some weeks. Dr. Dunbar tells me that three years ago the mother brought to her a male infant, one of twins, with a syphilitic lesion on the thigh which rapidly yielded to mercurial treatment. The mother becoming again pregnant fell into bad health, but quickly improved under similar measures which were continued till her confinement. As far as is known no fresh treatment was needed before the last confinement.

The necropsy was made 50 hours after death by Dr. J. M Clarke. It was noted that the body was stained a deep but bright yellow and that all the organs were similarly coloured. There was very little subcutaneous fat, but the heart and lungs were normal in every respect. The liver weighed about 11 ounces, which is nearly double the normal weight for a child of that age. It was of a very deep green olive or bronze colour and smooth in section. The substance of the organ was not friable or granular and, on the other hand, it was not specially hard. In the neighbourbood of the portal fissure there was much thickened connective tissue, and scattered through the liver around branches of the ducts there was an excessive amount of the same tissue. but this condition did not apparently extend through the whole substance. No concretions could be found in the gall-bladder or the ducts. A portion of the common duct was enormously distended and contained a clear fluid with deposits of dark pigment on the walls. 'The papilla of the common duct in the duodenum was prominent, and both in the portal fissure, in the mesentery, and behind the peritoneum were several enlarged firm glands of a reddish colour. On further examination the gall-bladder was tound to be thickened and apparently completely closed. No trace of the common duct could be discovered for half of its length; the distended portion was about an inch in length and of the size of a pigeon's egg. The spleen weighed five ounces and was large and firm with patches of thickening of the capsule. In the kidneys the cortex was swollen, but the capsule stripped easily. Microscopical examination of the liver showed extensive fibrosis mainly surrounding the lobules, but invading them in places and cutting off islets of liver cells. Small bile-ducts were numerous. Nowhere was there small-celled infiltration of the margin of the fibrous tissue which may be taken to indicate that the fibrosis was not pro. gressive. The liver cells showed no degeneration and the contents of the bile-ducts were dark and prominent.

By the kindness of Dr. Dunbar and Dr. Theodore Fisher I am able to give notes of two other cases observed by them and not previously recorded.

CASE 2.-Dr. Dunbar says: "I delivered Mrs. L_- of a living boy in 1877 who was deeply jaundiced at birth. The mother remarked at once upon the colour, adding that she had had another child like it who had died. I afterwards learnt that she had lost previously six children in early infancy, all born alive and all deeply jaundiced. They lived from a few days to a few weeks. J. L_ lived for secen months an uneasy existence, suffering from sickness and constipation. The diet was carefully regulated and every effort was made, more or less unsuccessfully, to procure a food acceptable to his digestive organs, 'The stools were hard and scanty and always smeared rather than incorporated with yellowi-h-brown colouring matter. I made a post-mortem examination and found the liver enlarged The bile-ducts seemed to me to be replaced by mere connective tissue, but the condition of the stools made me think that there must have been some communication, however minute, between the liver and intestine. On examina tion of the fresh liver tissue I could not satisfy myself that there was any definite cirrhosis or destruction of the cells Four out of 11 children of this family lived to adult life. One of them showed symptoms possibly due to hereditary syrhilis, but in the others none were observed."

CAsE 3.-Dr. Fisher writes: "A male child, A. Bwas first seen by me nine weeks after birth. It was then deeply jaundiced, of a dirty yellowish colour, with a tinge of green. 'The colour was sufficiently deep to be perceptible over the gums and soft palate. The child was thin and weighed only seven pounds, but could not be said to be either drowsy or restless and appeared fairly comfortable There was a rash on the buttocks very suggestive of syphilis. The liver could be felt one and a half 
inches below the costal margin and the spleen about three-quarters of an inch. The mother stated that the child had been of a deep yellow colour from the time of birth and that the motions were generally white, but sometimes of a pale yellow. There were five other children in the family alive and well, and the mother had had no miscarriages. During the time the child was under observation the bowels were moved three or four times daily. The motions were semi-solid and like white lead in consistence and colour. There was never a trace of yellow in them. The urine was of a reddish yellow and gave a marked reaction with nitric acid. The saliva was tested for the sulpho-cyanide reaction and gave a faint colour. Five weeks later the child died. The liver and spleen were found to be much enlarged. The gallbladder was present but the common duct could not be found. There was nothing noteworthy in any of the other organs. Microscopic sections of the liver showed wellmarked multilobular and monolobular cirrhosis and numerous small bile-ducts. Some of the bile-ducts were distended 'with dark material and dark granules were seen in many of the liver cells."

These cases, then, seem to be rare, for Rolleston can only find 59 recorded instances, of which three were operated upon, one of them, Treves's case, being successful. This last case, however, may be of a different kind, for the jaundice had not commenced till the third year instead of within a day or two of birth, and the patient was not operated upon till his nineteenth year. It has been stated that none of the typical cases survive more than eight months, mild ones may survive and be mistaken later for alcoholic cirrhosis in children. They must be carefully distinguished from simple icterus neonatorum and septic jaundice, though umbilical and other hæmorrhages seem not uncommon in them. In this patient no organisms except the bacillus coli were found in the dilated portion of the duct, and the general health remained good in spite of the extreme jaundice. Nor do they resemble the iotérie splénomégalique of French writers, which seems to occur in older children, and presents a gigantic spleen extending over a large part of the abdomen, and ascites, stunted growth, clubbed fingers, deep jaundice, and enlarged abdominal veins.

Perhaps the most common cause of large liver in childhood is syphilis. Syphilis cannot be traced in many of these patients with obliterated ducts, though Thomson thinks that it may intensify the morbid process at times. Moreover, the condition of the liver is quite unlike that which is due to the luetic infection. Finally, the anæmia with a large spleen and liver found in some rachitic and other children may produce slight jaundice, but it shows no other points of resemblance and is frequently cured.

The first question to be solved is whether the changes in the liver are prior to those in the ducts or vice vers $\hat{a}$. There no meconium has been passed the disease must have arisen at a very early stage of foetal life. but in this patient and several others neither white stools nor jaundice appeared for some time after birth. If yellow stools are passed for some days it seems strong evidence that the bile channels are open after birth and therefore that no congenital failure of development has existed. We can hardly weigh against this fact the cases referred to by Dr. Rolleston and Dr. Dunbar where the changes in the liver were slight and recent and those in the ducts well developed. If, however, we think that both changes may occur after birth in some patients from inflammatory processes, these cases are not without importance. 'Thomson, indeed, finds that instances have occurred where the jaundice was very deep and that yet the ducts were pervious. He adds that if death takes place early no lesion or only some thickening of the duct walls may be found, while it is in those who live some months that extreme degeneration and even complete absorption of the ducts are generally found. This would seem conclusive, but Thompson suggest that as the bile found is usually much thickened virtual obstruction of the ducts may have been the cause of the cirrhosis of the liver. However, it appears proved that the complete destruction of the ducts is a secondary process and the only likely explanation offered is that of Rolleston, that owing to their extreme narrowness at birth they are easily destroyed by catarrhal and other inflammation, just as stenosis of the larynx is found more commonly in children from a similar cause. In adults the causes of cholangitis are the presence of calculi and perhaps of typhoid bacilli. Indeed, the formation of calculi is referred by some writers to the presence of an infective agent leading to chronic catarrhal changes. Calculi are exceedingly rare in infants; only about eight have been placed on record. It would seem, therefore, that we must reject as causes either developmental failure or calculous obstruction, and recognise an inflammatory process occurring either in fotal life or afterwards affecting the liver, the ducts, and the bile itself in varying degrees ; and bearing in mind the presence of multilobular changes in some patients at least, there is evidence in favour rather of a descending infection than of one ascending the bile-ducts. The obliteration of the ducts is a later symptom due in part to mechanical factors.

We may now turn to another line of argument. The cirrhosis is largely of the monolobular or biliary type, though more or less mixed with the multilobular. What, then, is the cause of biliary cirrhosis? The best known class of cases is that known under the name of Hanot, which is usually regarded as infective in origin. Of late much evidence has been brought forward to show that some form of cirrhosis may be due to obstruction of the ducts. Cheadle, indeed, says that in the majority of cases of obstructive jaundice no cirrhosis follows, ${ }^{1}$ but Vaughan Harley and others have shown by experiments on animals that in them biliary cirrhosis can be produced by ligature identical anatomically with that seen in Hanot's form. Mangelsdorff in 1882 collected 184 cases in man of cirrhosis with duct obstruction and even argued that any form of cirrhosis might accompany this condition. Ford, reviewing the whole subject in the present year, ${ }^{2}$ found 24 additional cases and includes several of these congenital ones, though he omits alcoholic and syphilitic cases and those due to well-known poisons. $\mathrm{He}$ regards it as now certain that in animals a damming back of the bile leads of itself to cirrhosis, while in man cirrhosis also follows on obstruction, but this is due in part to the inflammatory conditions which are always present. The cirrhosis, moreover, cannot be anatomically differentiated from that seen in Hanot's type, but the general symptoms accompanying it are totally different.

Now in this patient and others the general clinical picture is much more like that of Hanot's type than that which Ford finds in cirrhosis due to obstruction. Ford, indeed, rather strangely reckons these congenital cases among his instances of obstructive cirrhosis in spite of his own teaching, perhaps from grouping them with the few instances of calculi recorded. Thus, in obstruction he points out that the course of the disease is acute, with rapid loss of flesh and symptoms of portal obstruction. Yet in this patient and others like him the course of the disease was chronic, without much emaciation or loss of appetite. There were no enlarged abdominal veins, or odema, or, until the final stage when nephritis had set in, any ascites. Indeed, but for the kidney poisoning there seemed no reason why he should not have lived a considerable time in fair health. Thomson remarks that the interference with the general nutrition is usually much less than might be expected and that ascites is only occasional in congenital disease. Of course, as obliteration of the ducts is added to the cirrhosis at a later stage we get absolute exclusion of the bile from the bowel without any intermission of symptoms and finally a fatal termination, while in the adults suffering from Hanot's disease there are intermissions. On the whole, then, we have in some of these cases at least a complete picture of hypertrophic biliary cirrhosis only different from that seen in adults by the results of a secondary obliteration of the bile-ducts. What the poison or infection is which leads to it is by no means certain. The gastro-intestinal disturbances in the parent during pregnancy occasionally noted may point to the source of the mischief as Rolleston suggests, but until we know the cause of the much-debated biliary forms of cirrhosis no conclusion is possible.

Clifton, Bristol.

\section{INUNCTION $v$. INTRA-MUSCULAR INJEC- TION IN THE TREATMENT OF SYPHILIS.}

By C. F. MARSHALL, M.D., B.Sc. VICT., F.R.C.S. ENG., ASSISTANT SURGEON TO THE HOSPITAL FOR DISEASES OF THE SKIN, BLACKFRIARS.

A COMPARISON of the different methods of treating syphilis is difficult owing to the length of time during which it is necessary for patients to be under observation. The present

2 American Journal of the Medical Sciences, January, 1901. 